\title{
Application of GC/MS method for the identification of brandies and cognacs
}

\author{
V.N. Vlassov*, D.S. Maruzhenkov \\ Russian Center for Tests and Certification, Food Instrumental Tests Laboratory, 31, Nahimovsky avenue, \\ 117418 Moscow, Russia
}

\begin{abstract}
Chromatographic profiles and mass spectrometric data for more than forty various types of brandies, cognacs and armagnacs were obtained using gas chromatography coupled with mass spectrometry (GC/MS). Twenty-three characteristic compounds were identified by means of mass spectral libraries and integrated using selected $\mathrm{m} / \mathrm{z}$ ratios. Some indexes related to consumer properties of drinks were calculated. The quality and the origin of examined brandies were evaluated using the GC/MS data.
\end{abstract}

Key words. brandy - quality control - index of age - syringaldehyde / vanillin ratio - level of esters of superior acids

\section{Introduction}

The quality control of alcohol drinks is of prime importance for market in Russia. The spirit distilled from wine and matured in oak barrel is sold under the different names as "brandy", "cognac", "armagnac" accordingly to area of production.

Alcoholic beverages of this type are imported from several countries neighboring Russia, including Armenia, Azerbaidjan, Moldova, and more distant from it, such as France, Greece, USA. They are subject to obligatory verification (certification) for the conformity to the national standards of alcohol drinks. However, the existing norms and methods provided by these documents do not seem to be sufficient for full estimation of the authenticity and quality of imported brandies. The sensorial testing remains the main method of grade assessment of drinks, while being the subjective judgement, it depends considerably on the expert's qualification.

Adulterations of different type can be found in market. Evident falsification, for example, brandy diluted with large volume of water and ethyl alcohol, coloured with caramel (burnt sugar) and flavoured with vanillin are easy to disclose by tasting. The verification of declared term of maturation (age) or the brand confirmation are much more difficult and require additional methods.

The countries located on the territory of the former USSR produce brandies of different grade with the age indicated on the label. Brandies of "ordinary" quality, which are sold as 3,4 or 5 "stars", are matured no less than 3,4 or 5 years. The age of brandies "of brand" and "of collection" quality subdivided as "matured", "matured of high quality", "old" and "very old" is no less than $6,8,10$ and 12 years corre- spondingly [1]. There are also brandies without any age indicated on a bottle. Usually they are produced from young spirits, sometimes with adding of oak wood extracts, and must be considered of inferior quality.

French cognacs and armagnacs have the following wellknown grades of quality: VS, VSOP, Napoleon, XO, Extra, Selection in order of increasing of the age and price. French brandies have no gradation related to the maturation process.

The adulteration of age is very profitable since the price rise quickly with the ageing time of spirits. Sometimes the difference between two drinks of different age amounts to as $100 \%$ of its price and even more.

A number of publications appeared recently confirm the keen interest for the oak wood composition and its influence on sensorial properties of alcohol drinks [2 - 4]. Natural polymeric pnenolic substances (lignins) were found to be suitable chemical markers of age of spirits [5]. The most modern instrumental methods of analysis were applied in this area, including the direct thermal desorption with GC/MS detection for quantifying volatile compounds in oak wood [6], capillary gas chromatography coupled with mass spectroscopy for the analysis of oak lignins in order to demonstrate the wine ageing [7], capillary electrophoresis for the characterization of brandies and wood extracts [8].

\section{Materials and methods}

\section{Chemicals}

All chemicals were reagent grade. Hexane, diethyl ether were bought from Merck. Ammonium sulfate is manufactured by BDH Laboratory Supplies. The internal standard 1, 
2, 4,5- tetramethyl benzene (durene) is a product of Aldrich. The solution of the internal standard in hexane with concentration of $500 \mathrm{mg} / \mathrm{L}$ was prepared. Water was deionized using the system Maxima (Elga, England) for ultrapure water.

\section{Provenance of samples}

In most cases, brandies and cognacs were delivered to the test center in order to obtain a licence for sale. Some of them were bought in free market. The series of thirteen Armenian brandies was acquired directly from producing company as verification standards.

\section{Chromatographic conditions}

The model GCQ (Finnigan MAT) GC/MS system equipped with autosampler, Gateway 2000 PC and data handling software was employed. The capillary column was a 30-m Rtx1701 (14\% cyanopropyl dimethyl polysiloxane) with an i.d. of $0.25 \mathrm{~mm}$ and $0.5 \mu \mathrm{m}$ of film thickness. Helium was used as carrier gas at the constant linear velocity of $35 \mathrm{~cm} / \mathrm{sec}$. All samples were injected splitless. The temperature of injection port was $220^{\circ} \mathrm{C}$ and the oven temperature was programmed from $35{ }^{\circ} \mathrm{C}(1 \mathrm{~min})$ to $250{ }^{\circ} \mathrm{C}(10 \mathrm{~min})$ at the rate of $7{ }^{\circ} \mathrm{C} / \mathrm{min}$.

\section{Mass spectrometry conditions}

Ionization was performed by electron impact with an electron energy of $70 \mathrm{eV}$. The temperature of external ion source of the ion trap mass spectrometer was $200{ }^{\circ} \mathrm{C}$. Full scan mode of data acquisition was applied through the mass range from 50 to $450 \mathrm{u}$ with a scan rate of $1 \mathrm{scan} / \mathrm{sec}$. The fol- lowing characteristic mass to charge ratios $(\mathrm{m} / \mathrm{z})$ were used for data calculation: durene (internal standard), 134; phenylethyl alcohol, 122; 3-ethylphenol, 107; 4-ethyl-2methoxyphenol, 137; 2-ethoxy-4-(2-propenyl)phenol, 178; furfural, 95; 5-hydroxymethyl-2-furancarboxaldehyde, 126; vanillin, 152; ethylvanillyl ether (ethylvanillin), 137; syringaldehyde 182; superior acids (octanoic, decanoic), 129. Ethyl esters of superior acids from hexanoic to octadecanoic, 157. Ethyl esters of acids: vanillic, 137; syringic, 226. Diethyl esters of acids: butandioic (succinic), 129; hydroxybutandioic (malic), 117; hexanedioic, 111.

\section{Extraction of samples}

Fifteen milliliters of brandy were added with 20 microliters of the internal standard solution, diluted (1: 1) with saturated ammonium sulfate solution and extracted with $5 \mathrm{ml}$ of diethyl ether / hexane mixture $(2: 1 \mathrm{v} / \mathrm{v})$. The organic layer was separated, concentrated under a nitrogen flow to about one milliliter volume and one microliter of the resulting extract was injected into the GC/MS system for analysis.

\section{Results and discussion}

\section{Data processing}

Figure 1 shows the example of chromatographic profile of 10-years Armenian brandy "Ahtamar". The numbered substances are identified by means of mass spectral libraries (NIST, Wiley). Obviously, the poor separation of some peaks obtained by the detection of total ion current and low sensitivity towards some components involves difficulties with
Corment: Brandy Ahtamar 10 years (Erevan, Armenia)

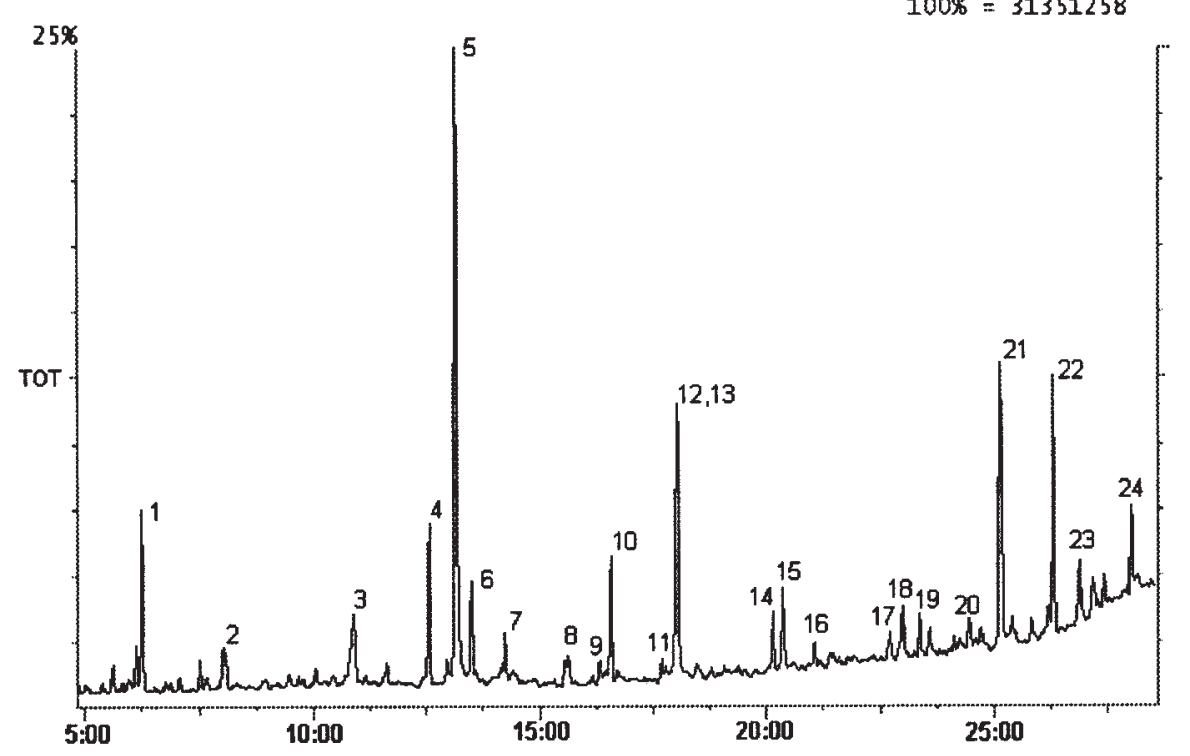

Fig. 1. Total ion chromatogram of the principal compounds of 10-years Armenian brandy "Ahtamar". 1: furfural; 2: hexanoic acid, ethyl ester; 3 : durene (internal standard); 4: octanoic acid, ethyl ester; 5: phenylethyl alcohol; 6: succinic acid, diethyl ester; 7: octanoic acid; 8: 3-ethylphenol; 9: 4ethyl-2-methoxyphenol; 10: decanoic acid, ethyl ester; 11: malic acid, diethyl ester; 12: decanoic acid; 13: 5hydroxymethyl-2-furancarboxaldehyde; 14: dodecanoic acid, ethyl ester; 15: vanillin; 16: hexanedioic acid, diethyl ester; 17: vanillic acid, ethyl ester; 18: 2-ethoxy-4-(2-propenyl)phenol; 19: tetradecanoic acid, ethyl ester; 20: ethylvanillin; 21: syringaldehyde; 22: hexadecanoic acid, ethyl ester; 23: syringic acid, ethyl ester; 24 : octadecanoic acid, ethyl ester. 
their integration. So we used the selected ions' intensity in order to avoid the problem. Peaks of interest were integrated using selected $\mathrm{m} / \mathrm{z}$ and their ratio to internal standard was utilized to calculate the indexes characterizing the composition of brandies.

\section{Method precision}

We have evaluated the method precision on example of 7years Armenian brandy "Otborny". Five consecutive extractions were performed and resulting extracts were analysed by GC/MS. Table I shows the distribution of the data received. The relative standard deviation (RSD) values for the most of the characteristic compounds are not big while some of them are less reproducible. The substances with the RSD-values more than $10 \%$ were rejected from the method developement.

\section{Indexes of authenticity}

Syringaldehyde and vanillin arise from the oxidative destruction of natural polymeric phenolic substances (lignins) of oak wood material during the ageing process. Thus, their concentration accumulated indicate the time of maturation in oak cask. We have accepted the relative intensity of syringaldehyde as the "index of age".

The "syringaldehyde/vanillin" ratio seems to be one of the characteristics of brandy's original composition. As usual the found content of syringaldehyde exceeds more than twice the vanillin content in oak wood specious [6]. The ratio will be disturbed if the additional amount of vanillin is added in order to adulterate original brandy.

Ethyl esters of some superior acids were reported to be responsible for the brandy's characteristic flavour [9]. The level of ethyl esters of superior acids, from octanoic to octadecanoic, is evidently a value specific of the manufacturing method. Some well-known brands of cognacs have a relatively high content of these components due to technological mode of production. Any illicit dilution of original brandy brings to the equivalent decrease of this index.

\section{Evaluation of grade}

Analytical results for over than forty brandies and cognacs produced in different countries reported in Table II. The values included prove the grade of old cognacs "Hennessy" and "Remy Martin", which contain a relatively high level of markers of age, whereas the quality of the other cognacs and armagnacs seems to be in accordance with their indexes found. All the cognacs examined (numbers 1 - 4) show a high content of ethyl esters of superior acids. The age of French brandies "Dorville Napoleon" and "Dorville Select" to all appearances is not high judging by the low value of index of age.

A large number of investigated brandies produced in Armenia, Moldova, Georgia and Azerbaijan were found to be corresponding with their declared grade. However, few adulterations were revealed (at the bottom of Table II). In
Table I. Dispersion of analytical results (on example of 7-years Armenian brandy "Otborny").

\begin{tabular}{lcc}
\hline COMPOUND & Mean value & RSD (\%) \\
\hline Furfural & 3.71 & 8.9 \\
Hexanoic acid, ethyl ester & 0.07 & 5.2 \\
Octanoic acid, ethyl ester & 0.24 & 2.4 \\
Phenylethyl Alcohol & 1.06 & 7.7 \\
Succinic acid, diethyl ester & 0.48 & 8.6 \\
Octanoic acid & 0.10 & 10.6 \\
Phenol, 3-ethyl- & 0.12 & 2.4 \\
Phenol, 4-ethyl-2-methoxy- & 0.13 & 6.5 \\
Decanoic acid, ethyl ester & 0.45 & 4.2 \\
Malic acid, diethyl ester & 0.07 & 25.1 \\
Decanoic acid & 0.10 & 11.8 \\
Furancarboxaldehyde, 5-(hydroxymethyl)- & 1.68 & 6.8 \\
Dodecanoic acid, ethyl ester & 0.18 & 5.3 \\
Vanillin & 0.36 & 9.5 \\
Hexanedioic acid, diethyl ester & 0.14 & 14.3 \\
Vanillic acid, ethyl ester & 0.02 & 40.7 \\
Phenol, 2-ethoxy-4-(2-propenyl)- & 0.271 & 26.1 \\
Tetradecanoic acid, ethyl ester & 0.12 & 5.4 \\
Ethyl vanillin & 0.18 & 15.1 \\
Syringaldehyde & 1.41 & 5.6 \\
Hexadecanoic acid, ethyl ester & 0.57 & 3.9 \\
Syringic acid, ethyl ester & 0.05 & 41.0 \\
Octanoic acid, ethyl ester & 0.05 & 6.6 \\
\hline & & \\
\hline
\end{tabular}

${ }^{1}$ Mean value of analysis of 5 samples (area of compound / area of internal standard)

the most cases they are very popular appellations of Armenian brandies. The level of accumulated phenolic substances showed by the former three brands is too poor by comparison with original products, whereas the others two brandies were diluted considerably and flavoured by a large amount of vanillin.

On the whole the index of age does not exceed the limit of 1.0 for brandies "of ordinary" quality up to 5 years, whereas old brandies aged more than 6 years are characterized by the values much higher (Fig. 2).

It should be noted that an uncertainty always exists when the verification of age or grade is made without any comparison with the authentic samples from the manufacturer. This is the result of various differences of manufacturing mode and materials used by the producers.

\section{Brand identification}

When the question of origin is raised, the total comparison of characteristic compounds with the help of statistic methods is needed. Brandies produced by the same manufacturer 
Table II. Characteristic indexes calculated from the GS/MS data of examined brandies.

\begin{tabular}{lccc}
\hline Number Brand name and the manufacturing country & $\begin{array}{c}\text { Age } \\
\text { (years) or grade }\end{array}$ & $\begin{array}{c}\text { Index of age } \\
\text { Syringaldehydel } \\
\text { Vanillin ratio }\end{array}$ & $\begin{array}{c}\text { Sum of esters } \\
\text { of superior acids }\end{array}$ \\
\hline
\end{tabular}

\begin{tabular}{|c|c|c|c|c|c|c|}
\hline & & Cognacs and Armagnacs & & & & \\
\hline 1 & France - & Bowen & VSOP & 0.92 & 2.68 & 3.60 \\
\hline 2 & & Chabasse & VSOP & 0.23 & 2.44 & 6.00 \\
\hline 3 & & Hennessy & XO & 2.91 & 3.25 & 4.86 \\
\hline 4 & & Remy Martin & $\mathrm{XO}$ & 4.73 & 3.72 & 4.58 \\
\hline 5 & & Cles des Ducs & 3 stars & 0.73 & 2.73 & 1.21 \\
\hline \multirow[t]{2}{*}{6} & & Chateau de Laubade & VSOP & 2.70 & 3.17 & 1.75 \\
\hline & & Brandies & & & & \\
\hline 7 & France - & Dorville Napoleon & - & 0.27 & 3.99 & 1.08 \\
\hline 8 & & Dorville Select & - & 0.25 & 4.04 & 1.26 \\
\hline 9 & Armenia $^{2}$ - & 3 stars & 3 & 0.46 & 4.16 & 1.71 \\
\hline 10 & & Ararat & 4 & 0.48 & 5.01 & 1.65 \\
\hline 11 & & 5 stars & 5 & 0.94 & 4.77 & 1.77 \\
\hline 12 & & Ararat & 6 & 1.38 & 4.54 & 1.77 \\
\hline 13 & & Ani & 6 & 1.43 & 4.41 & 1.57 \\
\hline 14 & & Otborny & 7 & 1.41 & 3.89 & 1.56 \\
\hline 15 & & Yubileiny & 10 & 3.75 & 4.76 & 1.86 \\
\hline 16 & & Ahtamar & 10 & 4.43 & 4.30 & 1.66 \\
\hline 17 & & Armenia & 10 & 3.69 & 4.57 & 2.02 \\
\hline 18 & & Dvin & 10 & 4.56 & 5.29 & 2.97 \\
\hline 19 & & Prazdnichny & 15 & 5.10 & 4.13 & 2.17 \\
\hline 20 & & Vaspuracan & 18 & 4.72 & 3.82 & 1.63 \\
\hline 21 & & Nairi & 20 & 7.36 & 4.15 & 1.96 \\
\hline 22 & Azerbaijan - & Gek-Gel & 5 & 0.87 & 3.04 & 1.05 \\
\hline 23 & & Baku & $8-10$ & 3.54 & 3.47 & 1.01 \\
\hline 24 & & Moscow & 12 & 3.72 & 4.54 & 0.93 \\
\hline 25 & & Chirvan & 15 & 3.15 & 3.56 & 0.98 \\
\hline 26 & Georgia - & Sarajichvili & 5 & 0.31 & 2.44 & 1.08 \\
\hline 27 & & Gremy & $8-10$ & 1.78 & 3.50 & 1.98 \\
\hline 28 & & Os & $10-12$ & 1.39 & 3.36 & 1.44 \\
\hline 29 & & Enisely & $12-14$ & 1.29 & 3.28 & 1.33 \\
\hline 30 & & Tbilisy & $15-20$ & 1.59 & 3.25 & 1.44 \\
\hline 31 & Moldova - & 3 stars & 3 & 0.30 & 4.13 & 0.93 \\
\hline 32 & & Bely aist & 4.5 & 0.76 & 4.33 & 1.50 \\
\hline 33 & & Basarabia & 15 & 2.27 & 2.94 & 2.52 \\
\hline 34 & & Solnetchny & 20 & 3.54 & 3.49 & 1.33 \\
\hline 35 & & Victoria & 25 & 5.28 & 3.20 & 1.97 \\
\hline 36 & & Yubileiny & 30 & 5.56 & 3.35 & 1.17 \\
\hline 37 & & Suvorov & 40 & 8.23 & 2.83 & 1.96 \\
\hline 38 & Russia - & 3 stars & 3 & 0.33 & 3.24 & 0.69 \\
\hline 39 & & 5 stars & 5 & 0.74 & 3.02 & 1.48 \\
\hline 40 & & Staraya krepost & $3-5$ & 0.26 & 4.18 & 0.67 \\
\hline \multirow[t]{7}{*}{41} & Bulgaria - & Slantschew brjag & 3 & 0.22 & 2.24 & 0.56 \\
\hline & & Adulterations of Armenia & & & & \\
\hline & & Ani & 6 & 0.42 & 3.27 & 0.73 \\
\hline & & Vaspuracan & 18 & 0.56 & 2.65 & 0.65 \\
\hline & & Nairi & 20 & 0.63 & 2.18 & 1.14 \\
\hline & & Ahtamar & 10 & 0.04 & 0.002 & 0.05 \\
\hline & & Yubileiny & 10 & 0.04 & 0.002 & 0.09 \\
\hline
\end{tabular}

\footnotetext{
${ }^{1}$ Age indicated on the label.

${ }^{2}$ Received from manufacturer as verification standards.
} 
Table III. Comparison of some old brandies and cognacs by correlation of their components $(\mathrm{n}=15)$.

\begin{tabular}{|c|c|c|c|c|c|c|c|c|c|c|c|}
\hline 1 & Hennessy (France) & 1.000 & 0.959 & 0.702 & 0.691 & 0.630 & 0.656 & 0.557 & 0.528 & 0.845 & 0.797 \\
\hline 3 & Yubileiny (Armenia) & & & 1.000 & 0.995 & 0.626 & 0.631 & 0.727 & 0.782 & 0.900 & 0.853 \\
\hline 4 & Ahtamar (Armenia) & & & & 1.000 & 0.682 & 0.685 & 0.753 & 0.804 & 0.905 & 0.860 \\
\hline 5 & Baku (Azerbaijan) & & & & & 1.000 & 0.995 & 0.791 & 0.819 & 0.842 & 0.793 \\
\hline 7 & Eniseli (Georgia) & & & & & & & 1.000 & 0.994 & 0.584 & 0.484 \\
\hline 8 & Tbilisi (Georgia) & & & & & & & & 1.000 & 0.574 & 0.473 \\
\hline 9 & Solnechny (Moldova) & & & & & & & & & 1.000 & 0.989 \\
\hline 10 & Suvorov (Moldova) & & & & & & & & & & 1.000 \\
\hline
\end{tabular}

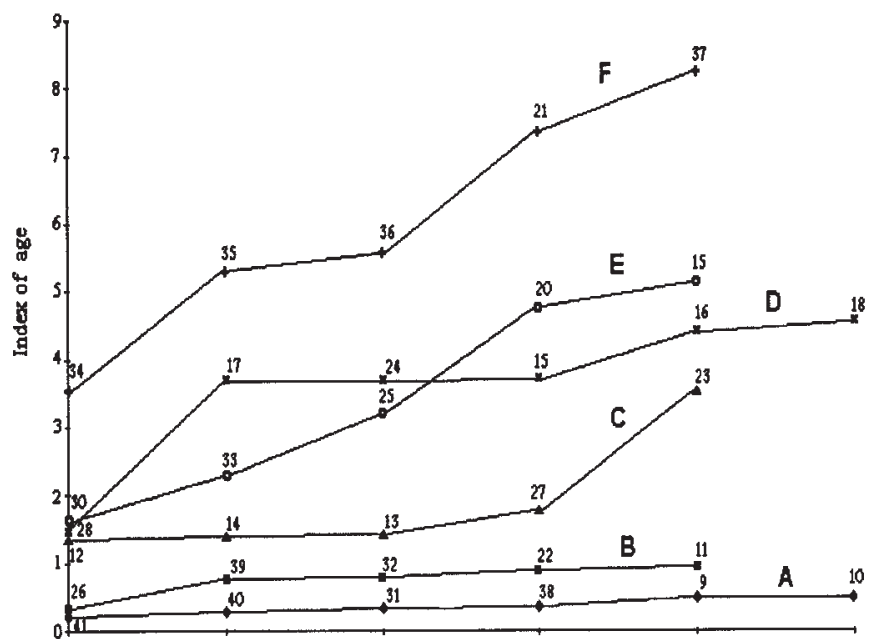

Fig. 2. Distribution of brandies according to the index of age (for the identification of numbers see Table II). Age: 3-4 years (A), 45 years (B), 6-10 years (C), 10-15 years (D), 15-20 years (E), 2040 years $(\mathrm{F})$.

should be similar on their composition taking into account that the materials and the technology are the same. We have compared ten old brandies and cognacs produced in different countries through the whole set of integrated peaks $(n=$ 15) using the procedure of correlation analysis (Table III). The drinks produced by the same manufacturer have the highest values of the correlation coefficient close to 1.000 .

\section{Conclusion}

The organoleptic testing being very important in quality assessment of drinks does not supply with any objective data. GC/MS, with its high selectivity and sensitivity, offers an advanced analytical method for the characterization of brandy composition. Some components are markers of important consumer properties.

This article describes the means to identify brandies or cognacs using the content and the correlation of their characteristic compounds. The calculation of some values from the analytical data is a simple way to compare this type of drinks, also more thorough comparison could be applied on the whole range of the components using statistical methods. The described procedure can be useful for the verification of brandies' quality and their brand identification.

\section{Acknowledgment}

The authors express their gratitude to Department for Standardization, Metrology and Certification of Armenia for granting the samples of original Armenian brandies.

\section{References}

1. Kishkovsky, Z.N.; Merganian, A.A. Technology of wine, Publishing house "Legkaya i pischevaya promyshlennost", Moscow, 1984.

2. Puech, J.-L. J. Int. Sci. Vigne Vin, 1992, 26, 81-91.

3. Chatonnet, P. J. Int. Sci. Vigne Vin, 1992, 26, 39-49.

4. Chatonnet, P.; Boirdon, J.N.; Dubourdieu, D.; Pons, M. J. Int. Sci. Vigne Vin, 1994, 28, 359-380.

5. Viriot, C.; Scalbert, A.; Lapierre, C.; Moutonnet, M. J.Agric.Food Chem., 1993, 41, 1872-1879.

6. Garcia-Romero, E.; Perez-Coello, M.S.; Sanz, J.;Cabezudo, M.D. Analusis, 1998, 26, 33-35.

7. Vivas, N.; Bourgeois, G.; Glories, Y.; Augustin, M.; Vitry, C. Analusis, 1998, 26, 88-92.

8. Rosario Bronze, M.; Vilas Boas, L.F. Analusis,1998, 26, 4047.

9. Pearson's Composition and Analysis of Foods, 9th ed./ R. S.Kirk, R.Sawyer, Longman Scientific \& Technical, 1991, 441. 